\title{
ENSINO DE ARTES, RELAÇÕES DE GÊNERO, SEXUALIDADE E DIVERSIDADE SEXUAL: NARRATIVAS DE ESTUDANTES GAYS
}

\section{ARTS EDUCATION, GENDER RELATIONS, SEXUALITY AND SEXUAL DIVERSITY: GAY STUDENT NARRATIVES}

DOI: http://dx.doi.org/10.5965/1984317815012019098

Pedro Paulo Souza Rios

Universidade Federal de Sergipe

peudesouza@yahoo.com.br

\author{
Alfrancio Ferreira Dias \\ Universidade Federal de Sergipe \\ diasalfranciof@gmail.com
}

Andre Ricardo Lucas Vieira Universidade do Estado da Bahia sistlin@uol.com.br

\section{RESUMO}

O presente estudo tem por objetivo analisar as intersecções a partir das aulas do componente curricular Ensino de Artes e as relações de gênero, diversidade sexual e sexualidade, vivenciadas por três estudantes gays, do primeiro ano do Ensino Médio, do Colégio Modelo Luiz Eduardo Magalhães em Senhor do Bonfim - Bahia. Para tanto, utilizamos a perspectiva teórica pós-crítica, a partir das narrativas (auto)biográficas. O estudo sinalizou que o componente Ensino de Artes se constitui enquanto espaço educativo agregador da diversidade sexual e de gênero. Contudo, foi possível perceber que a matriz curricular da escola não consegue abarcar questões presentes na contemporaneidade, negligenciando temáticas como gênero, diversidade sexual e sexualidade. Assim, as narrativas evidenciam uma intrínseca relação entre o Ensino de Artes e as questões de gênero dentro da escola. Compreender o Ensino de Arte enquanto componente curricular obrigatório no contexto escolar faz-se necessário, no entanto, compreendê-lo na perspectiva interdisciplinar, torna-se imprescindível, uma vez que a escola se configura enquanto espaço legítimo de interação das experiências dos sujeitos.

Palavras-chave: Ensino de Arte. Relações de Gênero. Narrativas Gays.

\section{ABSTRACT}

The present study aims to analyze the intersections from the classes of the Curriculum component Teaching of Arts and the relations of gender, sexual diversity and sexuality, experienced by three gay students, the first year of High School, Colégio Modelo Luiz Eduardo Magalhães in Senhor do Bonfim - Bahia. For this, we use the post-critical theoretical perspective, from the (auto) biographical narratives. The study showed that the Teaching of Arts component constitutes an educational space that aggregates sexual and gender diversity. However, it was possible to perceive that the curricular matrix of the school can not cover contemporary issues, neglecting issues such as gender, sexual diversity and sexuality. Thus, the narratives evidence an intrinsic relationship between the Teaching of Arts and the gender issues within the school. Understanding Art Education as an obligatory curricular component in the school context is necessary, but understanding it in an interdisciplinary perspective becomes essential, since the school is configured as a legitimate space for interaction of the subjects' experiences.

Keywords: Arts education. Gender Relations. Gay Narratives. 


\section{CONSIDERAÇÕES INICIAIS: A RELEVÂNCIA DO ENSINO DE ARTE}

Historicamente, nos processos pedagógicos alguns componentes curriculares têm sido negligenciados em detrimento de outros considerados "mais importantes". Nesse sentido, os componentes que abordam questões relacionadas às subjetividades dos sujeitos em seus processos formativos, dentre eles o Ensino de Artes, são vinculados à matriz dos considerados "menos importantes" e, portanto, recebendo uma atenção menor por parte do corpo docente e discente, e por vezes é possível perceber um silenciamento no que se refere aos referidos componentes "menos importantes" (FISCHER, 1983).

Nesse caso a não efetivação do componente Ensino de Artes implicará no descumprimento da Lei de Diretrizes e Base da Educação Nacional - LDB, 9394/1996, que estabelece em seu art. 26, $\S 2^{\circ}$ : "O ensino da arte, especialmente em suas expressões regionais, constituirá componente curricular obrigatório da educação básica" (BRASIL, 2017, p. 21).

Sobre isso, os Parâmetros Curriculares Nacionais - PCN's (1997, p. 37), para o Ensino de Artes enfatiza ser essa uma área do conhecimento, sendo parte constitutiva da base curricular das escolas "[...] requerendo, portanto, capacitação dos professores para orientar a formação do aluno". Assim, a arte é importante na escola, principalmente porque é importante fora dela. Por ser um conhecimento construído por homens e mulheres ao longo dos tempos, a Arte é um patrimônio cultural da humanidade e todo ser humano tem direito ao acesso a esse saber (BARBOSA, 2002).

Entendemos que o Ensino Arte, enquanto componente curricular obrigatório (BRASIL, 2017), pode se constituir em um espaço agregador de temáticas ligadas à formação das subjetividades dos sujeitos. Quando bem trabalhada, este componente estabelece conexões importantes com os demais componentes curriculares, além de suscitar sentimentos e sensações inerentes às identidades subjetivas dos/as estudantes, conforme sinaliza Saviani (2006). 
Os estudos de gênero e sexualidade e seus desdobramentos precisam adentrar os contextos da escola, não somente porque estão assegurados nos Parâmetros Curriculares Nacionais (BRASIL, 1998), nas Diretrizes Curriculares Nacionais Gerais da Educação Básica (BRASIL, 2013), antes porque a sexualidade é inerente ao ser humano e está presente em toda a vida do indivíduo e em todos os espaços e instituições. Consequentemente, tem uma relação intrínseca na formação do/a cidadão/ã, buscando conscientização e emancipação, pois é preciso compreender a relação da sexualidade enquanto algo prazeroso, consentâneo e também libertador.

Dessa maneira, o presente artigo tem por objetivo investigar, por meio das narrativas (auto)biográficas, como as questões de gênero e sexualidade vivenciadas por estudantes gays, do Colégio Estadual Luiz Eduardo Magalhães, em Senhor do Bonfim - Bahia, a partir do componente curricular Ensino de Artes, interferem no seu processo de formação, ao tempo em que busca compreender de que maneira as aulas de Artes influenciam na constituição da identidade de gênero dos estudantes e, ao fazer isso refletiremos como as identidades de gênero são produzidas e reproduzidas pelo currículo ao longo do processo de formação dos sujeitos.

Suscitamos, portanto, algumas indagações que irão nortear nosso estudo: 1. Quais são as possíveis relações entre o ensino de Artes e as questões inerentes às relações de gênero no espaço escolar?; e 2. O ensino de Artes pode se constituir efetivamente num componente curricular que abarque elementos que dizem respeito às subjetividades de gênero dos estudantes gays?

A escola tem se constituído, historicamente, um dentre outros espaços de saber legitimado, imbuída de ideologias manifestadas desde sua gestão pelo poder estatal, até o trabalho desenvolvido cotidianamente com a comunidade. Considera-se, nesta perspectiva, que a escolha curricular e metodológica dos/as professores/as expressa e instaura determinadas visões de mundo a partir de suas convicções ideológicas, políticas, religiosas, éticas e morais (MEYER, 2003). 
Contudo, o que se tem percebido nos espaços educativos é um descaso "natural" nas questões que dizem respeito às relações de gênero. Louro (2007) sinaliza ser mais cômodo para escola e seus agentes fingirem que nada está acontecendo, assim não há necessidade de refletir sobre o problema instaurado. Entretanto, o que se tem percebido é que os/as estudantes criam mecanismos para se reinventarem, se refazer e se reescrever, sempre que encontram lacunas ou brechas, onde eles/as possam se expressar livremente (LOURO, 2001). Nesse sentido, entendemos que o campo das artes na escola, por meio do componente Ensino de Artes tem se configurado enquanto "lacuna" onde os/as estudantes podem se expressar a partir das suas vivências de gênero e sexualidade.

\section{A ARTE ENQUANTO EXPRESSÃO HUMANA}

A Arte se constitui uma das manifestações culturais mais antigas da humanidade, sendo, portanto, uma expressão própria e indissociável do que venha a ser o humano. Diz respeito à necessidade de reinvenção permanente inerente ao bicho humano. Podendo ser percebida desde os primórdios, sendo revelada já nas primeiras ações humanas, numa relação de interação trabalho humano e natureza, caracterizada por meio das pinturas rupestres (FISCHER, 1983).

$\mathrm{Na}$ atualidade, não há como ignorar o papel vital que as artes exercem na vida contemporânea. Sendo quase impossível pensar qualquer expressão humana desvinculada pelo menos de uma, dentre as múltiplas manifestações artísticas, uma vez que a arte se configura enquanto expressão da presença humana no mundo, ao criar objetos e formas que representam suas vivências e o seu expressar de ideias, sensações e sentimentos e uma forma de comunicação (AZEVEDO JÚNIOR, 2007).

Ao interagirmos com o mundo, a Arte se constitui um modo específico de manifestação da atividade criativa dos seres humanos. Dessa maneira, a atividade criativa diz respeito à especificidade humana por sua capacidade de combinações de ideias, emoções, sentimentos e produções nas diversas áreas do conhecimento. Sendo assim, podemos dizer que a arte é uma experiência elucidada por meio do 
conhecimento humano, com o intuito de expressar seus sentimentos e vivências. Nessa perspectiva, concordamos com Van Gogh (2008, p. 39) ao afirmar que,

\begin{abstract}
A arte é o homem acrescentado à natureza, é o homem acrescentado à realidade, à verdade, mas com um significado, com uma concepção, com um caráter, que o artista ressalta, e aos quais dá expressão, resgata, distingue, liberta e ilumina.
\end{abstract}

A arte é, pois, implicamento livre da humanidade com a natureza, com a realidade social que a cerca e com suas subjetividades interpessoais atribuindo-lhes novos sentidos e significados, ao tempo em que ela própria se liberta. Dessa maneira, o mundo da arte pode ser observado, compreendido, apreciado e modificado em uma relação mútua e de respeito, tanto na esfera individual, quanto coletiva.

Se assim considerarmos, podemos dizer que a arte existe para embelezar o mundo, decorar a cotidianidade muitas vezes marcada pelo desencanto. A arte tem sido utilizada para explicar e descrever a história, expressar ideias, sentimentos, desejos, podendo ser uma manifestação subjetiva singular ou coletiva (FISCHER, 1983). O ato de criação artística não tem necessariamente que ser uma representação fiel do mundo vivenciado e experimentado. O/a artista tem a liberdade de expressar sua concepção, seu desejo, uma vez que a função da arte e o seu valor estão na representação simbólica das experiências humanas.

Partindo desse princípio, deve-se atentar para o fato de que cada sociedade cultiva diferentes estilos de fazer arte, uma vez que a cada sociedade ou cultura apresentam seus próprios valores, morais, estéticos, religiosos e artísticos, no entanto, a arte se manifesta de acordo com elas (AZEVEDO JÚNIOR, 2007).

A Arte, portanto, se constitui enquanto quimera, utilizada na tentativa de transformação da natureza, é por meio dela que homens e mulheres dão novas formas à sociedade, atribuindo-lhe novos significados à existência humana. Trata-se, portanto, de externar uma imaginação do que significa a realidade, assim, o/a artista 
é considerado/a, por princípio, um mágico, pois é capaz de transformar a realidade através da arte (FISCHER, 1983).

\subsection{O ENSINO DE ARTE: UM COMPONENTE CURRICULAR OBRIGATÓRIO}

A obrigatoriedade do Ensino de Arte é algo recente, datando a partir da LDB 9.394 de 1996. Foi exatamente a não obrigatoriedade do Ensino de Arte no currículo que levou os/as arte/educadores/as de todo país a se posicionarem politicamente e lutarem para que este ensino fosse inserido nas escolas.

Ao travarem a luta em defesa da obrigatoriedade do Ensino de Arte em todas as escolas do país, os/as arte/educadores/as, vislumbravam ainda sensibilizar, conscientizar e organizar os/as profissionais/as do ensino formal desta área do conhecimento para discutir sobre novas tendências para o ensino dela no âmbito escolar. Foi após a promulgação da LDB - 9.394/1996, que o ensino da arte passou a ser componente obrigatório em todos os níveis da educação básica, como forma de "promover o desenvolvimento cultural dos alunos" (BRASIL, 2017, p. 12).

Após a implantação desta Lei o Ministério da Educação e Desporto - MEC elaborou os Parâmetros Curriculares Nacionais, definindo que:

[...] é característica desse novo marco curricular a reivindicação de identificar a área por Arte (e não mais por Educação Artística) e de incluí-la na estrutura curricular como área com conteúdos próprios ligados à cultura artística, e não apenas como atividade (BRASIL,1997, p.30).

De acordo com o mesmo documento:

[...] a atual legislação educacional brasileira reconhece a importância da arte na formação e desenvolvimento de crianças e jovens incluindo-a como 
componente curricular obrigatório da educação básica. No ensino fundamental a Arte passa a vigorar como área de conhecimento e trabalho com as várias linguagens e visa a formação artística e estética dos alunos. A área de Arte, assim constituída, refere-se às linguagens artísticas, como as Artes Visuais, a Música, o Teatro e a Dança (BRASIL,1997, p.19).

$\mathrm{Na}$ contemporaneidade, o Ensino de Artes busca apresentar aos/às educandos/as diferentes possibilidades de aperfeiçoamento, saberes teóricos e práticos sobre arte, que surgem durante a proposição das múltiplas linguagens artísticas, estabelecendo aproximar o/a estudante com a sua própria natureza, considerando a sua identidade pessoal, sua história e sua cultura, fazendo com que ele/a compreenda como estes elementos podem se integrar na sociedade, ao tempo em que possibilita o autoconhecimento.

A escola deve ser, portanto, o local onde efetivamente crianças, jovens e adultos, podem vivenciar e entender os processos artísticos e sua história. Assim, a escola deve constituir-se em um espaço e tempo e por sua vez buscar a aquisição de novos saberes artísticos e estéticos. A formação escolar pode e deve contribuir para que os/as estudantes participem dessas vivências, desenvolvam novas habilidades, saberes básicos e significativos, possibilitando espaços de autoconhecimento por meio das múltiplas expressões artísticas.

\section{ARTE, GÊNERO E SEXUALIDADE NO AMBIENTE ESCOLAR: ENTRELAÇAMENTOS}

A contemporaneidade traz em seu bojo uma pauta que pensávamos já ter sido superada com o advento da era pós-moderna, caracterizada pela fluidez identitária, intimamente relacionada ao descentramento do sujeito (BAUMAN, 2003; HALL, 2006), favorecendo mudanças e ressignificações contínuas dos modelos de comportamento, estilos e a ausência de raízes, registrando-se o declínio das grandes narrativas modernas e das características morais ou éticas que as sustentavam anteriormente. 
A escola não reproduz ou reflete as concepções de gênero, diversidade sexual e sexualidade que transitam na sociedade, mas ela própria as produz (LOURO, 2007). Os indivíduos aprendem desde muito cedo, a reconhecer seus lugares sociais e aprendem isso através de estratégias muito difíceis de reconhecer. Dessa maneira, ao entendermos que as questões pertinentes às relações de gênero e sexualidade são moldadas e definidas por diferentes práticas discursivas, dentre elas as artes, compreenderemos que as produções artísticas e os discursos que circulam em torno delas colaboram para fixar e produzir identidades sexuais e de gênero, uma vez que as distintas expressões artísticas em seu processo de criação são perpassadas pelas subjetividades de gênero, étnica e geracional, dentre outras.

A reflexão em torno do respeito à diversidade de gênero tem melhorado significativamente as relações entre os distintos sujeitos, aguçando o interesse de estudiosos de diferentes áreas do conhecimento, em especial da educação, em pensar e organizar o currículo de tal forma que provoque na comunidade escolar o desejo de exercer o papel de espaço de promoção da inclusão, sem distinção de gênero, etnia, raça, geração, sexualidade, orientação sexual, ou quaisquer que sejam as diferenças.

\subsection{POR UM CURRÍCULO QUEER NO ENSINO DE ARTES}

$\mathrm{Na}$ década de 1970, queer foi uma expressão utilizada para ridicularizar os homossexuais, nos Estados Unidos. No Brasil tal expressão pode ser traduzida como estranho, esquisito e raro. No final da década de 1990 o termo foi recuperado positivamente pelas feministas estadunidenses, elaborando assim uma teoria subversiva e perturbadora sobre os gêneros e sexualidades desviantes, explorando as fissuras teóricas e políticas para se pensar e criticar as normas regulatórias da sociedade (LOURO, 2004).

De acordo com Butler (2015) os estudos queer se constituem num importante instrumento de pesquisa, pois possibilitam romper a continuidade, o fluxo enunciativo da construção de sujeitos retos/endireitados. Ele é empregado em um sentido de 
"degradação" do sujeito ao qual se refere. Entretanto, possibilita a construção de novas linhas de constituição a partir de referentes até então não inteligíveis.

A Teoria Queer se inscreve nas discussões atuais sobre gênero e sexualidade inspirada nas concepções pós-estruturalistas de sociedade, de conhecimento, de cultura, de política como forma de desestabilizar os modelos hegemônicos de vivência do gênero e da sexualidade (LOURO, 2004).

O currículo escolar sempre esteve implicado na construção das identidades e das diferenças: "desde a sua constituição, a escola moderna é marcada por diferenças. [...] ela continua sendo, para crianças e jovens, um local importante de vivências cotidianas específicas e, ao mesmo tempo, plurais" (MEYER, 2003, p. 35). Porém, não havia a preocupação em questioná-la e problematizá-la. Dessa forma, o currículo tem legitimado identidades hegemônicas ocidentais, brancas, masculinas, heterossexuais e contribuindo para posicionar as não hegemônicas como inferiores, deficitárias, patológicas, desviantes e comumente silenciadas. Da mesma maneira que tem legitimado a arte unicamente na perspectiva eurocêntrica deslegitimando as expressões artísticas populares, classificando-as apenas como folclore. De acordo com Silva (2005, p. 109),

Um currículo inspirado na teoria queer é um currículo que força os limites das epistemes dominantes: um currículo que não se limita a questionar o conhecimento como socialmente construído, mas que se aventura a explorar aquilo que ainda não foi construído.

Podemos inferir que essa falta de preocupação em questionar quais identidades o currículo produz está ligada ao fato de que a escola e, consequentemente, o currículo, surgiu "[...] inicialmente para acolher alguns - mas não todos - ela foi, lentamente, sendo requisitada por aqueles/as aos/às quais haviam sido negadas. Os novos grupos foram trazendo transformações à instituição" (LOURO, 2007, p.57). 
O currículo contém um discurso que constrói as múltiplas identidades dos sujeitos (SILVA, 2005). O currículo pode contribuir para manter ou para eliminar a dicotomia feminino/masculino, branco/negro, jovem/idoso ensinando que uma pessoa pode ou não ter exclusivamente atributos convencionalmente denominados masculinos e femininos, reduzindo, ou não, o masculino a macho e feminino a fêmea, restringindo ou não os modelos de feminilidade e masculinidade, podendo perpetuar ou transformar a desigualdade de gênero, típicas das sociedades ocidentais e das culturas androcêntricas. Para Silva (2005, p 99), a teoria queer "é a diferença que pode fazer a diferença no currículo".

O currículo escolar precisa ser pensando e estruturado de tal maneira que o/a estudante encontre nele significados, de modo a responder efetivamente à diversidade da escola, dando a ela uma educação de qualidade. O reconhecimento sobre questões relacionadas à diversidade no contexto escolar é o primeiro passo para evitar que as diferenças, sejam culturais, étnicas, religiosas, sociais, de gênero, entre outras, transformem-se em desigualdades e desvantagens entre os educandos. Faz-se necessário educar então, tendo como base o respeito às singularidades de cada estudante, o que podemos chamar de uma educação para a diversidade.

Uma proposta curricular pautado na Teoria Queer possibilitaria pensar novas estratégias pedagógicas que sejam não-normativas, envolvendo, portanto, as distintas expressões humanas e artísticas muitas vezes consideradas estranhas e incompreendidas por aqueles/as que acreditam que a arte pode ser "enquadrada" em um modelo único.

\section{METODOLOGIA: PERCURSO DA PESQUISA}

No que concerne aos fundamentos metodológicos, esse estudo é de caráter qualitativo, a partir das narrativas (auto)biográficas no campo educacional. Pesquisadores como Nóvoa (1993, 2000), Josso (2006) Souza (2006a, 2006b), entre outros, têm apresentado trabalhos significativos nessa área, que versam desde a constituição do educador reflexivo até a formação inicial e continuada dos 
profissionais da educação, perpassando ainda pelos processos pedagógicos de ensino-aprendizagem. Conforme Souza,

\begin{abstract}
Nas pesquisas na área de educação adota-se a história de vida, mais especificamente, o método autobiográfico e as narrativas de formação como movimento de investigação-formação, seja na formação inicial ou continuada de professores/professoras ou em pesquisas centradas nas memórias e autobiografias de professores (SOUZA, 2006a, p. 23).
\end{abstract}

As narrativas como metodologia de pesquisa valorizam e exploram as dimensões pessoais dos sujeitos, seus afetos, sentimentos e trajetórias de vida, e levam à percepção da complexidade das interpretações que os sujeitos pesquisados fazem de suas experiências e ações, sucessos e fracassos e dos problemas que enfrentam. Por sua vez, a investigação narrativa recorre às explicações dadas pelos indivíduos para entender as causas, intenções e objetivos que estão por trás das ações humanas.

Em relação ao método, entendemos que a Fenomenologia, por procurar compreender os fenômenos subjetivos na crença de que verdades essenciais acerca da realidade são baseadas na experiência vivida, aliado à pesquisa biográfica, ajudaram na elucidação das indagações e propostas, pois, segundo Abrahão (2004), na pesquisa qualitativa não se objetiva explicar o fenômeno, mas compreendê-lo, auxiliando no autoconhecimento do indivíduo e deste para com o mundo.

\title{
3.1 INSTRUMENTOS E LÓCUS
}

Quanto aos instrumentos metodológicos para a coleta de dados utilizamos as entrevistas narrativas (auto)biográficas, que se configuram enquanto atividade formadora no processo de formação e de conhecimento (SOUZA, 2006b). Para Bauer e Gaskell (2002) a entrevista narrativa vai além do esquema "pergunta-resposta". Considerada um procedimento do tipo qualitativo, ela é entendida como uma entrevista não estruturada, com tipos específicos de comunicação - linguagem 
espontânea -, o contar e escutar histórias para se alcançar os objetivos desejados na pesquisa. Porém não significa dizer que a entrevista narrativa não esteja formalmente estruturada, pois ela segue um esquema, como dissemos acima, onde o informante, no caso aqui a (o) docente, usa sua própria linguagem (BAUER e GASKELL, 2002).

As narrativas foram gravadas individualmente entre março e junho de 2017 , num total de sete narrativas. Sendo três de Luiz, duas de Eduardo e duas com Magalhães, considerando a disponibilidade de tempo e dúvidas posteriores a serem sanada com cada um dos sujeitos, num total de 4 hs 46 min de gravação. É importante ressaltar que optamos por utilizar nomes fictícios. Dessa maneira, nossos colaboradores de pesquisa são denominados de Luiz, Eduardo e Magalhães, fazendo alusão ao lócus de pesquisa.

Quanto ao campo de pesquisa, Arroyo (2011) sinaliza que na contemporaneidade, os territórios de identidade se configuram em espaços de ressignificação e construção/reconstrução das identidades de gênero, sexual, classe, raça, etnia, campo, cidade e periferia.

O lócus da pesquisa foi o Colégio Modelo Luiz Eduardo Magalhães, situado na cidade de Senhor do Bonfim, no Território Baiano de Identidade Norte do Itapicuru. A escolha pelo colégio se deu por considerarmos que ele agrega o maior contingente de estudantes do Ensino Médio no Munícipio de Senhor do Bonfim, funcionando nos turnos matutino, vespertino num total de Hum mil e cinquenta e sete estudantes.

\subsection{COLABORADORES DA PESQUISA}

No que se refere aos colaboradores da pesquisa, é pertinente ressaltar que a escolha se deu a partir de um levantamento prévio, considerando o período de quatro semanas de observação, com acompanhamento da professora durante as aulas do componente Ensino de Artes, em três turmas do Primeiro Ano do Ensino Médio, do Colégio Estadual Luiz Eduardo Magalhães - Senhor do Bonfim - Bahia. 
Posteriormente, foi feito o acompanhamento de atividades práticas do Ensino de Artes, onde os/as estudantes e a professora do componente curricular estavam preparando a culminância da II Semana de Ciências das Escolas da Rede Pública Estadual do Território Piemonte Norte do Itapicuru.

Considerando o período de observação em sala de aula e as atividades práticas, priorizou-se para esse estudo, três estudantes, sendo que a idade se constituiu um elemento preponderante na nossa escolha. Dessa forma, os três sujeitos da nossa pesquisa são maiores de idade.

Luiz tem dezoito anos, mora com a mãe, uma irmã e um irmão. Ao perguntarmos como ele se definia, o mesmo foi contundente na resposta rápida, curta e segura: "Sou uma pessoa feliz e incompreendida" (Entrevista, 20/03/2017). Sobre sua defasagem em relação série/idade ele comenta que: "Quando eu era mais novo não gostava de vim pra escola. Eu já lacrava desde pequeno e as professoras mandava eu me comportar". E continua: "[...] mas queria participar das apresentações de arte então tinha que tá matriculado [...]" (Entrevista, 20/03/2017).

Eduardo tem dezenove anos. Mora com pai/mãe e uma irmã. Na nossa primeira entrevista nos contou: "Não sei quem sou eu... pergunta difícil essa [...] Nem sempre as pessoas me entendem... mesmo gostando de brincar sou uma pessoa séria" (Entrevista, 12/03/2017). Sobre sua vida escolar nos disse que: "[...] às vezes tenho a sensação que a escola não foi feita pra todo mundo [...] já era pra ter concluído o ensino médio, mas ainda tem coisas que nem eu entendo" (Entrevista, 12/03/2017).

Magalhães tem dezenove anos. Mora com a avó, uma tia e um tio. Ele nos conta que: "Ser negro e gay não é nada fácil... esse sou eu!" (Entrevista, 15/04/2017). E continua: "Demorou muito tempo pra eu entender quem era eu... eu acho que ainda não sei direito, mas já aprendi que ser negro e ser gay não é fácil”. Sobre a escola ele narra que "[...] sou repetente... não gosto da escola, mas sem estudar não vou conseguir sem ninguém na vida" (Entrevista, 15/04/2017).

Buscando perceber as categorias recorrentes nas narrativas de Luiz, Eduardo e Magalhães entrecruzam-se o fato de serem gays e assumirem abertamente a 
orientação sexual. Outro elemento comum é a defasagem série/idade e a origem social, todos oriundos de famílias pobres, bairros periféricos e consequentemente marginalizados. Contudo, o que há de mais comum entre eles é a paixão pelas artes, sendo o Ensino de Artes o componente que os aproxima, já que os três são de salas distintas.

\section{NARRATIVAS SOBRE SER GAY E ARTISTA: VIVÊNCIAS DE GÊNERO}

"A arte me salvou! Ela me faz ver as coisas de outra forma".

LUIZ (Entrevista, 12/04/2017).

"Sem arte minha vida não tem sentido [...] por meio dela eu compreendo a vida em sociedade ". EDUARDO (Entrevista, 12/03/2017).

"Não sei o que seria de mim se não fosse a arte [...] se hoje eu penso e sei o que é cultura é graças a arte”. MAGALHÃES (Entrevista, 03/05/2017).

Iniciamos esta seção fazendo uma breve análise das epígrafes acima. É pertinente dizer que elas são fragmentos retirados das narrativas dos nossos sujeitos de pesquisa. As narrativas na íntegra constituem relatos vivenciais que marcam as trajetórias de pessoas tão jovens e já marcadas pelo sofrimento e pela exclusão, mas acima de tudo são sujeitos perpassados pelas vivências artísticas, a ponto de atribuírem sentido à vida associando-a ao universo artístico, fundamentando, dessa maneira, o que rege a LDB acerca da obrigatoriedade do Ensino de Artes "de forma a promover o desenvolvimento cultural dos alunos" (BRASIL, 2017, p. 12). Podemos assegurar que quando o Ensino de Artes é efetivamente legitimado pela escola, por meio de um currículo que leve em consideração a vida dos/as estudantes, fazendo 
com que eles/elas ousem transpor barreiras impostas por um sistema excludente, conforme narra Luiz ao falar sobre o ensino de artes: "[...]. Ela me faz ver as coisas de outra forma" (Entrevista, 12/04/2017). Já Eduardo comenta que "[...] é por meio da arte eu compreendo a vida em sociedade" (Entrevista, 01/06/2017). Nesse sentido, Magalhães relata que o ensino de artes contribuiu na formação do pensamento cultural crítico: "[...] se hoje eu penso e sei o que é cultura é graças à arte" (Entrevista, 05/06/2017).

Dessa forma, podemos evidenciar que as expressões artísticas estão presentes de maneira intrínseca no cotidiano desses sujeitos. $O$ universo habitado pelos seres humanos é o mesmo universo embelezado pelas artes, dividimos os mesmos espaços, ainda que não percebamos. Somos acometidos/as a todo o momento por uma música, uma tela, uma poesia, uma pintura, uma dança. Comumente é ela que se aproxima da gente, mas nós também nos aproximamos dela.

Nesse sentido, a escola tem se mostrado ser um espaço favorável às expressões artísticas, prova disso é o Festival Anual da Canção Estudantil - FACE, criado em 2008 pela Secretaria de Educação do Estado da Bahia, ampliado posteriormente para outras expressões artísticas. De acordo com Eduardo "O FACE é um dos momentos mais importantes da escola [...] é quando nós temos acesso à arte de verdade" (Entrevista, 12/03/2017). Para Magalhães "o festival é um momento bafônico, todo mundo junto [...] todos em favor da arte" (Entrevista, 03/05/2017). Já Luiz define o festival como sendo: "a expressão mais forte de que quando os alunos querem eles fazem a coisa acontecer [...] mas eu te confesso uma coisa professor, quem mais fecha é as bibas e as monas [...]" (Entrevista, 20/05/2017).

Um olhar mais atento é o suficiente para nos darmos conta de que, historicamente, as atividades vinculadas ao universo artístico costumam ter uma presença significativa de pessoas do seguimento LGBTQI, e constituindo algo recorrente nas distintas expressões artísticas. Conforme foi evidenciado na narrativa de Luiz,

Eu sempre me achei meio artista, desde criança gostava de me expressar e a arte ajuda muito é... como eu posso dizer? A arte me entende, na arte eu 
posso ser quem eu sou, eu uso a máscara para se eu mesmo, entende? A arte me ajudou a entender o que é ser gay [...] A escola tem ajudado muito nesse sentido, mas acaba taxando a gente, de vez em quando. Assim... todo mundo fala: 'é arte? Chama as bichas!' Uma prova disso é o Festival, as bichas e as monas chegam chegando. A gente fecha mesmo. Já que é pra lacrar a gente lacra! (Entrevista, 20/05/2017).

De acordo com Luiz a arte é algo inerente à sua condição, "desde criança" e por meio da arte ele procurou se conhecer e se aceitar enquanto sujeito, ajudando-o a compreender sua sexualidade. Contudo, ao adentrar a escola percebe que há uma barreira, um impedimento. Ao narrar que a escola "acaba taxando", taxar aqui é determinar o que pode e/ou não ser feito por um estudante gay. É impor limites, regular o corpo (LOURO, 1996).

Dentro da diversidade sexual, os grupos de gays, lésbicas, travestis e transexuais são vítimas de preconceitos e discriminações, devido à sua orientação sexual e identidade de gênero. A prática de homofobia na escola é um fator relevante na disseminação do preconceito, conforme sinaliza Eduardo:

Não é fácil ser gay, mas eu gosto de ser como eu sou [...]. Às vezes eu me sinto mal, eu fingo que não vejo, levo na brincadeira porque se não a gente fica louco [...] até me perdi [...] mas o que eu quero dizer com tudo isso é que tem gente preconceituosa disfarçada de amiga. Tem professores preconceituosos sim! Vixe Maria! Se fosse botar chocalho ninguém dormia nessa cidade, ia ser um barulho daqueles [..] mas dentro da escola eles têm que me engolir. O momento em que eu me sinto mais eu é nas aulas de arte [...] na verdade é assim... eu aproveito desses momentos pra mostrar quem realmente eu sou (Entrevista, 01/06/2017).

A fala de Eduardo evidencia que o preconceito ainda é algo presente na escola e ela continua fingindo que está tudo resolvido, enquanto os/as estudantes estão sendo vítimas de preconceitos e de homofobias.

A gente tá aqui (se referindo a escola) de ousado, porque se fosse ouvir as piadinhas já tinha desistido [...]. A gente começa a ouvir piadinhas quando sai de casa... é um vizinho grita: 'vai pra escola aprender a ser bicha é?', mas eu 
nem ligo, no fundo é inveja da bicha. As piadas elas não param aí, aqui dentro é piadinha o tempo inteiro, mas a gente fecha é no mundo das artes. Nesse mundo não tem pra ninguém [...] (MAGALHÃES, Entrevista, 15/04/2017).

Nos fragmentos apresentados, ao declarar 0 amor pelas artes, os colaboradores desse estudo acabam denunciando o preconceito presente dentro e fora da escola, deixando transparecer que o preconceito fora da escola é compreensível, tanto que Magalhães relata nem ligar. Contudo, quando o preconceito adentra a escola a sensação é que não há mais a quem recorrer: "Tem professores preconceituosos, sim!" Denuncia Eduardo. Mesmo assim, a escola ainda é um lugar de vivências da diversidade. Continua Eduardo: "[..] mas dentro da escola eles têm que me engolir!" (Entrevista, 01/06/2017).

De acordo com Louro (2007), o preconceito relacionado à sexualidade e à orientação sexual na escola é assunto cuja abordagem é muito delicada, tanto pelo corpo discente, quanto pelo corpo docente, tornando-o um tabu. Eduardo conclui: "Todo mundo na escola sabe que tem um monte de "viados" e "sapatas", mas ninguém toca no assunto". Relacionado isso Luiz Comenta:

\begin{abstract}
Esse assunto é algo misterioso aqui na escola. Não entendo essas coisas, juro pra você [...] a escola tem "viado" e "mona" pra dar de pau. Todo mundo brinca com a gente, mas na hora de falar sério sobre essas questões, aí já sabe né? Então o que é que gente faz? Quando falo a gente me refiro ao "viados" e "sapatas"... a gente rouba a cena, literalmente [...] nas apresentações é só o que a gente quer. Se tem quadrilha a gente lacra. Se é a fanfarra, essa é melhor abafar [...] só o povo do clube [...]. Eu já disse isso antes, mas não me canso de dizer: Eu me considero um artista, mas não sou qualquer artista, sou um artista gay! [...] Lacrei não foi? Porque eu sou desses [...] deixa eu me comportar, deixar de fechação [...] Assim, quando eu digo que me considero um artista é porque a arte me acolheu. Eu sempre gostei da disciplina de Artes na escola [...]. Foi ela quem me achou no processo de descoberta da minha orientação. Até hoje eu gosto muito dessa disciplina [...] ela me entende. Tô com pena de tu [...] já viu que sou uma matraca né? Não paro de falar (Entrevista, 20/03/2017).
\end{abstract}

Durante a gravação das narrativas com Luiz era notória a empolgação dele. Tinha algo de autoafirmação. A necessidade de alguém que o escute, já que ele/eles 
nunca são levados a sério: "todo mundo brinca com a gente" (Entrevista, 20/05/2017). Tal constatação só evidencia que as questões ligadas ao campo das relações de gênero, sexualidade, diversidade e orientação sexual ainda são negligenciadas pela e na escola. Uma vez que não consta no currículo, professores/as e estudantes não se sentem comprometidos com tal realidade, então o que lhe resta é a arte "porque a arte me acolheu" (LUIZ, Entrevista, 12/04/2017).

Nessa perspectiva, Louro (1996) salienta que a negação dos/as homossexuais na escola acaba por confiná-los/as às "gozações". Como bem reflete Eduardo: "O tempo inteiro as pessoas brincam com a gente, mas no fundo a vontade de muitos era de acabar com a gente. Eu sinto que muitas vezes são "gozações" em forma de brincadeira".

As aulas de Ensino de Artes se constituíram nos momentos mais desejados pelos/as estudantes/as que de alguma maneira se sentiam excluídos/as da matriz curricular convencional. Sobre isso, foi possível constatar durante as observações, que a professora desse componente sempre apresentava uma dinâmica de integração e entrosamento dos/as estudantes antes de iniciar aulas, contextualizando os conteúdos que seriam trabalhados posteriormente. Magalhães nos conta que: "As aulas de artes são diferentes [...] são mais atrativas" (Entrevista, 03/05/2017). Eduardo é mais enfático ao afirmar que: "Nas aulas de arte o conteúdo tem um significado pra gente" (Entrevista, 12/03/2017). Sobre isso, Luiz ressalta a possibilidade de interdisciplinaridade contida no Ensino de Artes: "A gente aprende sobre arte, história, cultura, sobre a vida, sobre a sociedade, sobre política [...]" (Entrevista, 20/03/2017).

Durante as gravações foi possível constatar que tanto Luiz quanto Eduardo e Magalhães demostraram ter especial dedicação pelo componente Ensino de Artes: "Eu não escondo de ninguém o quanto eu gosto da disciplina de Artes. Fico só imaginando no próximo ano, já não terei mais essa disciplina" (EDUARDO, Entrevista, 01/06/2017). Sobre isso Luiz é enfático: "Já falei com a diretora: posso até passar de ano, mas as aulas de artes eu não perco por nada nesse mundo" (20/05/2017). Sobre isso Magalhães afirmou que: "Quando tem aula de artes eu venho para escola mais animado" (Entrevista, 15/04/2017). 
Dessa maneira as narrativas de Luiz, Eduardo e Magalhães sinalizam uma intrínseca relação entre o componente curricular Ensino de Arte e as questões inerentes às relações de gênero, sexualidade, orientação sexualidade dentre outras. Assim, entendemos que compete à escola desenvolver ações interdisciplinares a partir de um currículo que esteja flexível e aberto às diferenças que adentram o ambiente escolar. Nessa perspectiva, acreditamos que o componente Ensino de Artes pode se constituir num agregador, aproximando, portanto, currículo, professores/as, estudantes, tornando a escola num espaço equitativo.

\section{5 (IN)CONCLUSÕES ACERCA DO ENSINO DE ARTE E A ARTE DE SER GAY}

$\mathrm{Na}$ tentativa de narrarmos algumas (in)conclusões podemos dizer que a arte se constitui enquanto forma de expressão humana, tendo em vista que ela transmite características e conceitos inerentes aos sujeitos e sua cultura, uma vez que é por meio dela que homens e mulheres conseguem expressar ideias, sensações e sentimentos, servindo como uma forma de comunicação

Cada lembrança, cada fala, cada gesto, cada frase inacabada era seguida ora de arroubos festivos, ora de uma leve e passageira melancolia. Por duas vezes Eduardo chegou a se emocionar: "Desculpas pelas lágrimas... eu não imaginava que isso fosse acontecer! [...] É a primeira vez que eu paro pra contar minha história [...]. De longe parece que é só alegria, mas também tem tristezas" (Entrevista, 01/06/2017). Vez por outra eles se davam conta que nossa conversa estava sendo gravada "eita, esqueci que isso é coisa séria e o professor tá gravando" (Entrevista, 20/05/2017), comentou Luiz algumas vezes, voltando a agir naturalmente logo depois.

Dessa maneira, pode-se dizer que compreender o Ensino de Arte enquanto componente curricular obrigatório no contexto escolar faz-se necessário, no entanto, compreendê-lo na perspectiva interdisciplinar torna-se imprescindível, uma vez que a 
escola se configura enquanto espaço legítimo de interação das experiências dos sujeitos.

De modo geral, a escola por meio de seus agentes e currículos, negligenciam questões que tratam das temáticas acima mencionadas. As narrativas nos possibilitaram perceber que o Ensino de Artes pode ser um componente curricular agregador e de respeito às diferenças de gênero e à diversidade sexual, uma realidade silenciada nos espaços educativos.

\section{REFERÊNCIAS}

ABRAHÃO, Maria Helena Menna Barreto. Pesquisa (auto)biográfica: teoria e empiria. Porto Alegre: EDIPUCRS, 2004.

ARROYO, Miguel Gonzales. Currículo, Território em Disputa. Rio de Janeiro: Vozes, 2011.

AZEVEDO JUNIOR, José Garcia de. Apostila de Arte - Artes Visuais. São Luís: Imagética Comunicação e Design, 2007.

BUTLER, Judith. Corpos que ainda importam. Sapere Aude - Belo Horizonte, v.6 - n.11, p.12-16 $-1^{\circ}$ sem. 2015 . ISSN: $2177-6342$

BAUMAN, Zygmunt. Modernidade Líquida. Tradução: Plínio Dentzien. Rio de Janeiro: Zahar, 2003.

BARBOSA, Ana Mae. Inquietações e mudanças no ensino de arte. São Paulo: Cortez, 2002.

BRASIL. Secretaria de Educação Fundamental. Parâmetros curriculares nacionais: primeiro e segundo ciclos do ensino fundamental (Tema Transversal Sexualidade). Brasília: MEC/SEF, 1998.

BRASIL. Secretaria de Educação Fundamental. Parâmetros curriculares nacionais: Ensino de Artes. Brasília: MEC/SEF, 1997.

Brasil. Diretrizes Curriculares Nacionais Gerais da Educação Básica. Ministério da Educação. Secretária de Educação Básica. Diretoria de Currículos e Educação Integral. Brasília: MEC, SEB, DICEI, 2013.

BRASIL. LDB: Lei de Diretrizes e Bases da Educação Nacional. - Brasília: Senado Federal, Coordenação de Edições Técnicas, 2017.

FISCHER, Ernst. A Necessidade da Arte. Rio de Janeiro: Zahar, 1983. 
BAUER, Martin Wien; GASKELL, George. Pesquisa qualitativa com texto, imagem e som: um manual prático. Petrópolis, RJ: Vozes, 2002.

HALL, Stuart. A identidade cultural na pós-modernidade. Rio de Janeiro, DP\&A, 2006. JOSSO, MARIE-CHRISTINE. Experiências de vida e formação. São Paulo, Cortez, 2006.

LOURO, Guacira Lopes. (Org.). O corpo educado. Belo Horizonte: Autêntica, 1996.

LOURO, Guacira Lopes. Currículo, Género e Sexualidade. Porto Editora. Porto: Portugal, 2001.

LOURO, Guacira Lopes. Um corpo estranho: ensaios sobre sexualidade e teoria queer. Belo Horizonte: Autêntica, 2004.

LOURO, Guacira Lopes. Gênero, sexualidade e educação: Uma perspectiva pósestruturalista. Petrópolis - RJ: Vozes. 2007.

MEYER, Dagmar Estermann. Gênero e educação: teoria e pratica. Em G. L. Louro;J.F. Neckel \& S. V. Goellner 9Orgs.), Corpo, gênero e sexualidade: um debate contemporâneo na educação (pp.9-27). Petrópolis: Vozes, 2003

NÓVOA, Antonio. Formação de professores e profissão docente. In: NÓVOA, António (Org.). Os professores e a sua formação. Lisboa: Dom Quixote, 1993.

NÓVOA, Antonio. Os professores e as histórias da sua vida. In: NÓVOA, António (Org.) Vidas de professores. Porto: Porto, 2000.

SAVIANI, Dermeval. As concepções pedagógicas na história da educação brasileira. Campinas: Histedbr, 2006.

SILVA, Tomaz Tadeu da. Documentos de Identidade: uma introdução às teorias do currículo. Belo Horizonte: Autêntica, 2005.

SOUZA, Elizeu Clementino. A arte de contar e trocar experiências: reflexões teóricometodológicas sobre história de vida em formação. Revista Educação em Questão, Natal, v.25, n. 11 , p. 22 - 39, jan./abr., $2006 a$.

SOUZA, Elizeu Clementino. O Conhecimento de si - Estágio e narrativas de formação de professores. Salvador, BA, UNEB, 2006b.

VAN GOGH, V. Cartas a Théo. 2. ed. Porto Alegre: L\&PM, 2008. 